\title{
Ferromagnetic Schottky junctions using diamond semiconductors
}

\author{
T. Soumiya, K. Ueda, N. Fukatani, T. Miyawaki and H. Asano \\ Dept. of Crystalline Materials Science, Graduate School of Engineering, Nagoya Univ., \\ Furo-cho, Chikusa-ku, Nagoya 464-8603, Japan
}

\begin{abstract}
Ferromagnetic Schottky junctions using $\mathrm{Co}_{1-\mathrm{x}} \mathrm{Fe}_{\mathrm{x}}$ or $\mathrm{Ni}_{1-\mathrm{x}} \mathrm{Fe}_{\mathrm{x}}(\mathrm{x}=0 \sim 1)$ were fabricated on H-terminated diamond and their interfacial characteristics were evaluated. A clear work function dependence of the Schottky barrier height $\left(\Phi_{\mathrm{B}}\right)$ was obtained for these junctions, indicating that the Schottky barrier height between H-terminated diamond and ferromagnetic metals can be controlled by selecting metals with appropriate work functions. $\Phi_{\mathrm{B}}$ for $\mathrm{Ni}$ and $\mathrm{NiFe}$, which have higher work functions above $5 \mathrm{eV}$, is lower than $\Phi_{\mathrm{B}}$ for other ferromagnetic metals. These results indicate that ferromagnetic metals with higher work function are promising for spin injection into diamond semiconductors.
\end{abstract}

Key words: diamond film, semiconductor, Schottky junction, ferromagnet, CVD

\section{ダイヤモンド半導体を用いた強磁性ショットキー接合の作製}

宗宮嵩・植田研二・深谷直人・宮脇哲也・浅野秀文

名古屋大学 大学院工学研究科 結晶材料工学専攻, 愛知県名古屋市千種区不老町 (厂464-8603)

\section{1. はじめに}

半導体スピントロニクスにおける最も重要な課題の 1 つは，強 磁性電極から半導体への高効率スピン注入の実現である. 現在, $\mathrm{Si}, \mathrm{GaAs}$ などの半導体への強磁生体電極からの効果的なスピン注 入方法が広く研究されているが 1,2)，未だ半導体と強磁性体電極の 最適な組み合わせや高効率スピン注入の方法は確立していない.

ダイヤモンドはワイドギャップ半導体(バンドギャップ $5.5 \mathrm{eV}$ ) の一つであり, 高い熱伝導率 $\left(22 \mathrm{~W} \mathrm{~cm}^{-1} \mathrm{~K}^{-1}\right)$, 高いキャリア移動度 $\left.\left(\sim 4500 \mathrm{~cm}^{2} \mathrm{~V}^{-1} \mathrm{~s}^{-1}\right)^{3}\right)$, 高い 破壊電界強度 $(10 \mathrm{MV} / \mathrm{cm})$ など優れた特 性を持っており, これらの特性は高速電子デバイス, 高出力電子デ バイスに有利である. 近年、我々が作製した水素終端化学蒸着 (CVD) ダイヤモンド電界効果トランジスタでは遷移振動数 $\left(f_{\mathrm{T}}\right)$ が $45 \mathrm{GHz}$, 最大発振振動数 $\left(f_{\max }\right)$ が $\left.120 \mathrm{GHz}{ }^{4}\right), 1 \mathrm{GHz}$ での最大出 力密度が $2.1 \mathrm{~W} / \mathrm{mm}$ であり 5)，ダイヤモンドが高出力半導体デバ イスとして高いポテンシャルを有していることを示している.

このようにダイヤモンドは次世代パワー半導体として期待され ているが，我々は次の 3 点の理由からスピントロニクス材料とし ても有望であると考えている.（1)ダイヤモンドを構成する炭素は 軽元素であるため, スピン一軌道相互作用が弱く, 長スピン拡散 長が期待できる, (2)高濃度ボロンドープによる低抵抗(金属)ダイヤ モンドを用いることにより, 強磁性電極の伝導率ミスマッチによ るスピン注入率の低下を回避できる 6,7$),(3)$ 化学安定性が高いため, ダイヤモンド強磁生体接合での界面反応を抑制できる.

現在，ダイヤモンドはスピントロニクス材料として検討されて おらず，またスピン注入に関する報告例もない，本研究では，ダ イヤモンド強磁性体へテロ接合を作製し，界面特性について調査 し, ダイヤモンドへのスピン注入に適したスピン源(強磁性体)の探 索を行ったので報告する.

\section{2. 実験方法}

ホモエピタキシャルダイヤモンド薄膜は, $1 \mathrm{~b}(100)$ ダイヤモンド (3 mm 角)基板を用い，マイクロ波プラズマ CVD 装置により作製

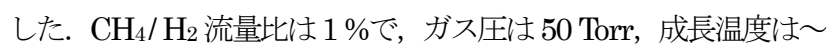
$700^{\circ} \mathrm{C}$, 膜厚は $1 \mu \mathrm{m}$ とした. ダイヤモンド薄膜の光学, 電気特 性はカソードルミネッセンス(CL) とホール効果測定により評価し た. CL測定は, 液体ヘリウム泠却ステージを装着した走査型電子 顕微鏡で行い，加速電圧は $10 \mathrm{kV}$ とした. ホール効果測定は, 0.5 Tの磁場中での van der Pauw 法で行った.

イオンビームスパッタリング装置を用い, 様々な強磁性体 $\left(\mathrm{Co}_{1 \mathrm{x}} \mathrm{Fe}_{\mathrm{x}}, \mathrm{Ni}_{1-\mathrm{x}} \mathrm{Fe}_{\mathrm{x}}(\mathrm{x}=0\right.$ ～1))薄膜をダイヤモンド薄膜上に室温 で成長させた. 強磁性薄膜の構造解析は $\mathrm{Cu} K_{\alpha}$ 線を使用した X 線回折法(XRD)で行った. 水素終端ダイヤモンド薄膜上にメタル マスクとフォトリソグラフィーを用いて, 強磁性ショットキー電 極として $\mathrm{Co}_{1 \times \mathrm{x}} \mathrm{Fe}_{\mathrm{x}}, \mathrm{Ni}_{1 \times \mathrm{x}} \mathrm{Fe}_{\mathrm{x}}$ (接合面積 : $\left.100 \mu \mathrm{m} \Phi\right)$, オーミック電 極として Au を用いたショットキーダイオードの作製を行った.

\section{3. 結果と考察}

\section{1 ダイヤモンド半導体特性}

Fig. 1 に $8 \mathrm{~K}$ と室温(RT)でのダイヤモンド薄膜 の CL スペクト ルを示す. $8 \mathrm{~K}$ での 235, 242, 233, $238 \mathrm{~nm}$ のピークはそれぞ れ, 横光学モードフォノンを供う自由励起子関連発光(FE'T), $\mathrm{FE}^{\mathrm{TO}}$ のフォノンレプリカ $\left(\mathrm{FE}^{\mathrm{TO}+\mathrm{O}}\right)$, 音響フォノン吸収による自由 励起子関連発光 $\left(\mathrm{FE}^{\mathrm{TA}}\right)$, 不純物ホウ素関連の束縛励起子発光 (BE $\left.{ }^{\mathrm{TO}}\right)$ である. 一般的に CL スペクトル強度は, 温度の上昇に伴 い減少していく.この現象は温度消光効果と呼ばれ, 温度増加に 伴い非輻射遷移の確率が大きくなることに起因すると考えられて おり, $8 \mathrm{~K}$ のみでなく室温でも $\mathrm{FE}^{\mathrm{TO}}$ が明確に観測できることから， 高品質ダイヤモンド薄膜が作製できている事が分かった. また， 8 $\mathrm{K}$ で観測できる $\mathrm{BE}^{\mathrm{TO}}$ はダイヤモンド薄膜中に存在する意眓的に 
ドープしていないホウ素(B)による発光であり， $\mathrm{BE}^{\mathrm{TO}} / \mathrm{FE}^{\mathrm{TO}}<$ 0.04 であることから，ホウ素濃度が $10^{15} \sim 10^{16} \mathrm{~cm}^{-3}$ 程度と見積も られる ${ }^{8)}$. 次に室温ホール効果測定から求めた水素終端ダイヤモン ド薄膜のキャリア濃度が 〜 $1.1 \times 10^{13} \mathrm{~cm}^{-2}$, 移動度が $~ 82$ $\mathrm{cm}^{2} / \mathrm{Vs}$ となった. これらの值は、従来の報告值 $\left(\sim 10^{13} \mathrm{~cm}^{-2}\right.$, $\sim 100 \mathrm{~cm}^{2} / \mathrm{Vs}$ ) $\left.{ }^{9}\right)$ と一致し、高品質な水素終端ダイヤモンド半導 体層が作製できている事がわかる. 酸化処理により水素終端を除 去した後にホール効果測定を試みたが，抵抗が高く測定出来なか った. CL 測定とホール効果測定の結果は，ダイヤモンド薄膜の電 気伝導は水素終端層による伝導が主体である事を示している.
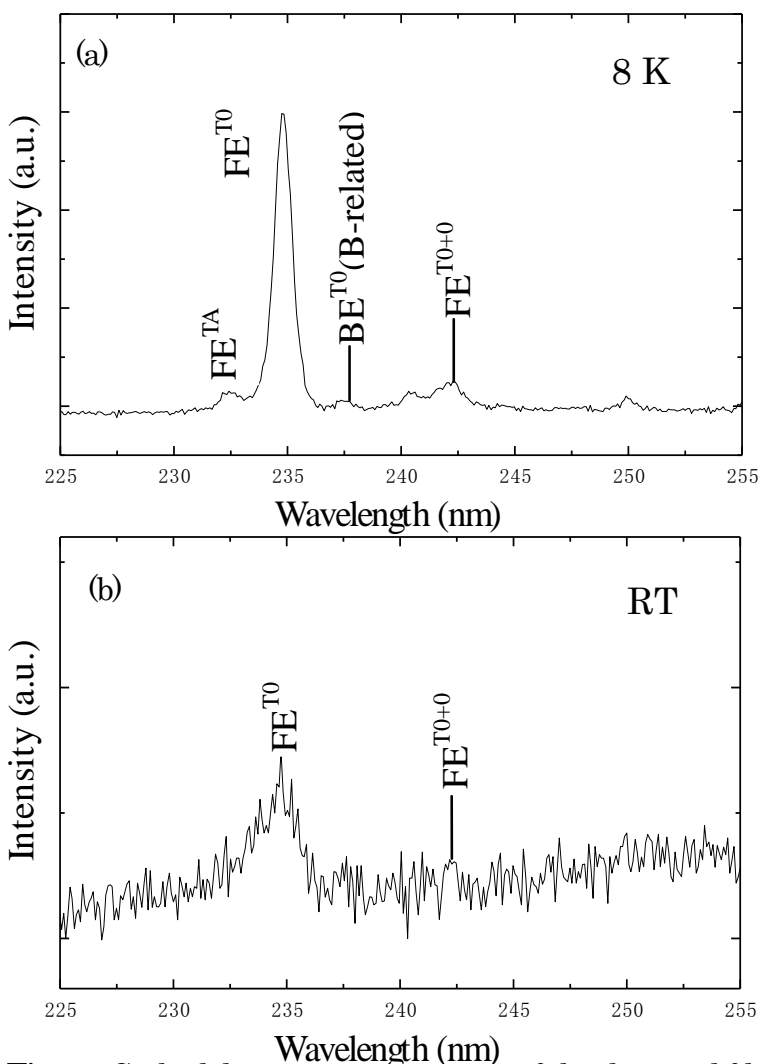

Fig. 1 Cathodoluminescence spectra of the diamond films measured at (a) $8 \mathrm{~K}$ and (b) room temperature (RT).

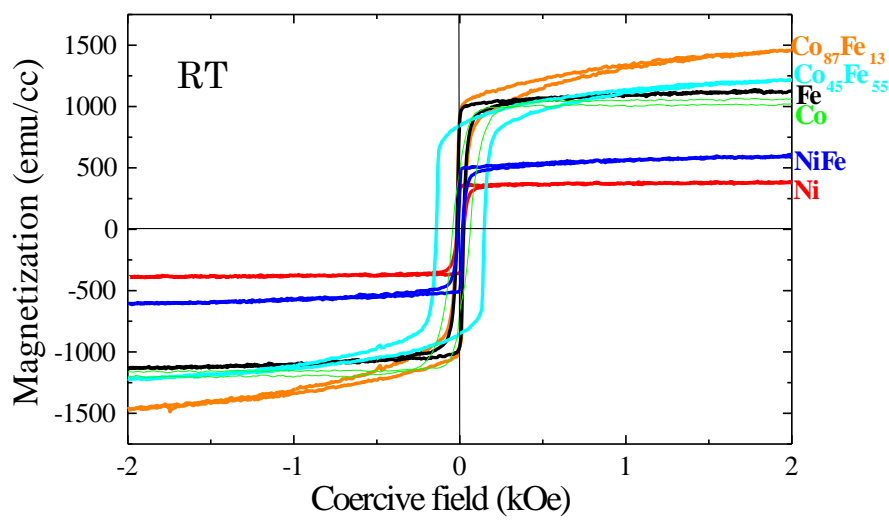

Fig. 2 Magnetic field dependences of the magnetization of various ferromagnetic films formed on diamond measured at room temperature.

\section{2 ダイヤモンド半導体/強磁性体の磁気特性}

Fig. 2 にダイヤモンド上に作製した様々な強磁生体の室温での 磁化曲線を示す.すべての強磁性体でヒステリシスが観測出来, 強磁生を示寸事が確認された. 飽和磁化 $\left(M_{\mathrm{s}}\right)$ と保磁力 $\left(H_{\mathrm{c}}\right)$ はそれぞ れ, Ni (370 emu/cc, 18 Oe), NisoFe20(575 emu/cc, 18 Oe), Co(1040 emu/cc, $21 \mathrm{Oe}), \mathrm{Co}_{87} \mathrm{Fe}_{13}(1370 \mathrm{emu} / \mathrm{cc}, 24 \mathrm{Oe}), \mathrm{Co}_{45} \mathrm{Fe}_{55}(1200$ $\mathrm{emu} / \mathrm{cc}, 140 \mathrm{Oe}), \mathrm{Fe}(1114 \mathrm{emu} / \mathrm{cc}, 18 \mathrm{Oe})$ である. これらの值は $\mathrm{Fe}$ を除き強磁性薄膜の理論值とほぼ等しい值である. $\mathrm{Fe} の M_{\mathrm{s}}$ が 小さい理由は, 後述する様に $\mathrm{Fe} /$ /゙イヤモンド界面での反応の影響 だと考えている. XRD パターンは載せていないが, すべての強磁 性体で関連ピークが確認できずアモルファス，または微結晶的で あった.

\section{3 ダイヤモンド半導体/強磁性体の電流一電圧特性}

ダイヤモンド半導体 / 強磁性体接合をそれぞれの強磁性体に対 し 5 8 素子作製した. Fig. 3 に様々なダイヤモンド半導体 / 強磁 性体の電流一電圧 $(\mathrm{I}-\mathrm{V})$ 特性を示寸. 全ての強磁性体接合で整流性 があり, $\mathrm{CoFe}\left(\mathrm{Co}_{87} \mathrm{Fe}_{13}, \mathrm{Co}_{45} \mathrm{Fe}_{55}\right)$ では 4 林, その他の強磁生体 では〜2桁の整流性が得られた. $\mathrm{CoFe}$ の整流性が良好な理由とし ては, 他の強磁性体に比べ高いショットキ一障壁高さを有してい ることと関係があると思われる．また，以下の熱電子放出モデル の方程式で $\mathrm{I}-\mathrm{V}$ 特性のフィッティング行い，算出した理想因子 $(n)$ とショットキー障壁高さ $\left(\Phi_{\mathrm{B}}\right)$ を Table 1 に示した.

$$
I=I_{S}\left[\exp \left(\frac{q V}{n k T}\right)-1\right], I_{S}=A_{e} A^{*} T^{2} \exp \left(\frac{-q \phi_{B}}{k T}\right)
$$

ここで, $\mathrm{A}^{*}$ はリチャードソン定数(ダイヤモンドは $\left.90 \mathrm{~A} / \mathrm{cm}^{2} \mathrm{~K}^{2}\right)^{10}$ ), $\mathrm{k}$ はボルツマン定数, $\mathrm{A}_{\mathrm{e}}$ は電極面積, $V$ はバイアス電圧, $I_{\mathrm{s}}$ は飽和 電流である. $n$ 值は報告されているボロンドープダイヤモンドを用 いたショットキー接合の值に比べ大きいが 10)，これは水素終端の 不均一性やダイヤモンド表面欠陥によるものと考えており, ダイ ヤモンド薄膜の更なる成長条件最適化により改善可能であると思 われる.

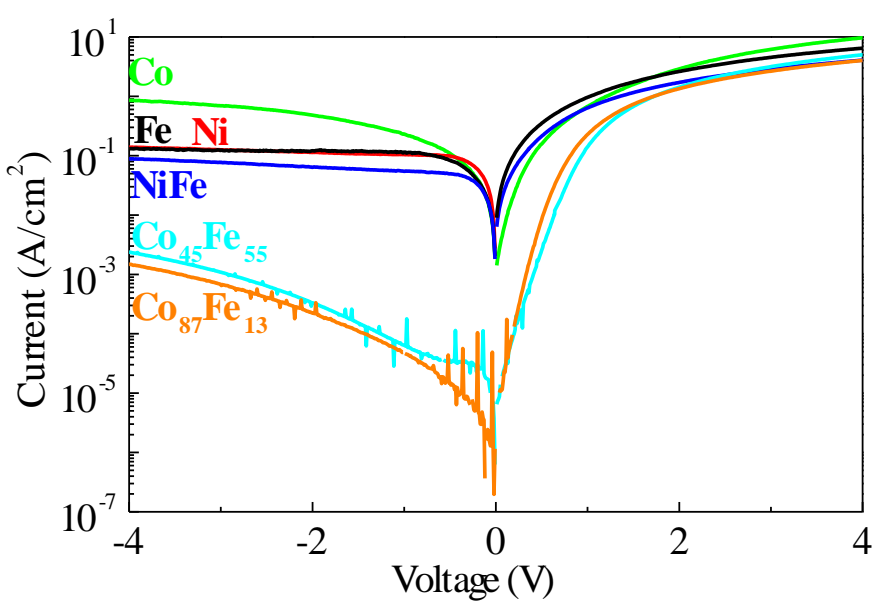

Fig. 3 Current-voltage characteristics for various diamond/ferromagnet heterojunctions. 
Table 1 The ideality values $(n)$ and barrier heights $\left(\Phi_{\mathrm{B}}\right)$ estimated from fittings of the current-voltage curves using eq. (1). The work functions of the ferromagnetic metals are also shown ${ }^{11)}$.

\begin{tabular}{|c|c|c|c|}
\hline & Work function $(\mathrm{eV})$ & $n$-value & $\Phi_{\mathrm{B}}(\mathrm{eV})$ \\
\hline $\mathrm{Fe}$ & 4.50 & 11 & 0.46 \\
\hline $\mathrm{Co}_{45} \mathrm{Fe}_{55}$ & 4.70 & 3.7 & 0.70 \\
\hline $\mathrm{Co}_{87} \mathrm{Fe}_{13}$ & 4.94 & 2.6 & 0.71 \\
\hline $\mathrm{Co}$ & 5.00 & 5.8 & 0.54 \\
\hline $\mathrm{Ni}_{80} \mathrm{Fe}_{20}$ & 5.01 & 4.6 & 0.46 \\
\hline $\mathrm{Ni}$ & 5.15 & 4 & 0.57 \\
\hline
\end{tabular}

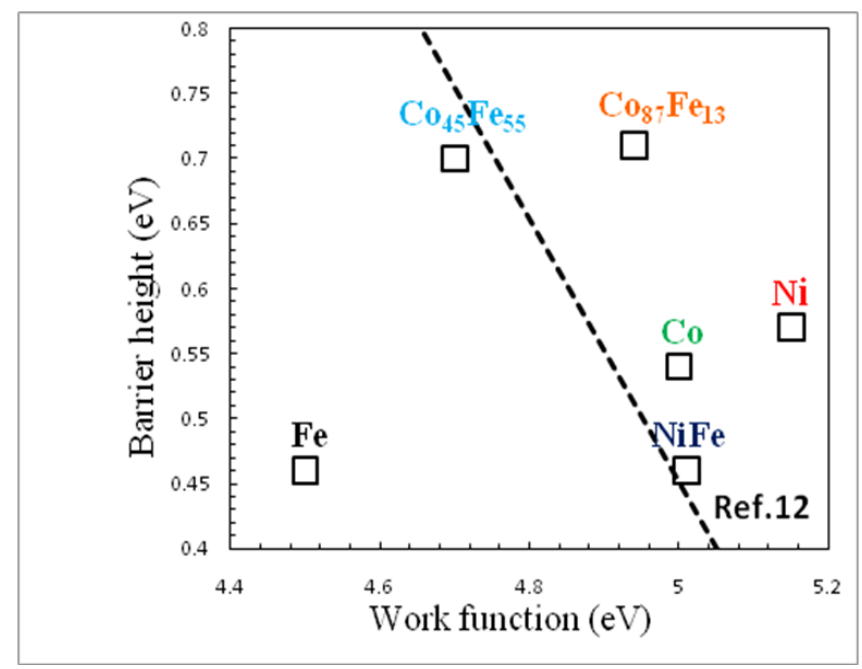

Fig. 4 Work function dependence of Schottky barrier heights $\left(\Phi_{\mathrm{B}}\right)$ for various ferromagnetic metals on diamond. The black dotted line shows work function dependence of $\Phi_{\mathrm{B}}$ from Ref.12.

\section{4 仕事関数とショットキー障壁高さ $\left(\Phi_{\mathrm{B}}\right)$ の関係}

Fig. 4 に様々なダイヤモンド半導体/強磁性体での仕事関 数とショットキー障壁高さ $\left(\Phi_{\mathrm{B}}\right)$ の関係を示す。ここで, $\mathrm{Co}(5.0 \mathrm{eV}), \mathrm{Ni}(5.15 \mathrm{eV}), \mathrm{Fe}(4.5 \mathrm{eV})$ などの強磁性金属の 仕事関数の值は Michaelson の結果から引用した ${ }^{11)}$. CoFe や $\mathrm{NiFe}$ のような合金の仕事関数は，それぞれの元素の組 成比から算出した。例として, $\mathrm{Co}_{87} \mathrm{Fe}_{13}$ の仕事関数は 4.94 $\mathrm{eV}(=0.87 \times 5.0 \mathrm{eV}(\mathrm{Co})+0.13 \times 4.5 \mathrm{eV}(\mathrm{Fe}))$ と見積もって いる．算出した $\Phi_{\mathrm{B}}$ の值は, Fe を除いて外部報告(Ref.12) の水素終端ダイヤモンド/金属接合でのショットキー障壁 高さの仕事関数依存性に近い值を示している。ピニング寄 与の可能性は排除できないが，このように金属仕事関数 $\left(\Phi_{\mathrm{M}}\right)$ が大きくなるほど $\Phi_{\mathrm{B}}$ の值が低くなっている．これら のことから, 酸素終端ボロンドープダイヤモンドではピニ ングによりショットキー障壁高さが一定值となるため $\Phi_{\mathrm{M}}$ による $\Phi_{\mathrm{B}}$ の制御が困難だが 13$)$, これに対し水素終端ダイ ヤモンドでは適当な $\Phi_{\mathrm{M}}$ を持つ強磁性体を選択することに
より $\Phi_{\mathrm{B}}$ を制御できる可能性が示された。これは，スピン 注入を行う上で大きな利点である.

また，Fe の場合は他の強磁性体と異なる傾向となった. この原因については明確でないが，我々は $\mathrm{Fe} /$ ダイヤモン ド界面で反応が起こった影響と考えており, $\mathrm{Fe} て ゙ の \mathrm{n}$ 值が 他の強磁性体に比べ 1 桁大きいことが界面での反応を示し ていると考えている. 実際 Aoki らにより，ポイントコンタ クトに比べ蒸着で作製した素子が界面の反応により $\mathrm{n}$ 值が 悪くなった結果が報告されている ${ }^{14)}$. なお, Fe とダイヤモ ンドは $800^{\circ} \mathrm{C}$ 以上の高温で反応し，炭化鉄を形成すること はよく知られている ${ }^{15)}$. 本研究では Fe の成長を室温で行 ったが，イオンビームスパッタリング法を用いたことによ り高いエネルギーが加わり反応性が向上したと考えている. また, $\mathrm{CoFe}\left(\mathrm{Co}_{87} \mathrm{Fe}_{13}, \mathrm{Co}_{45} \mathrm{Fe}_{55}\right)$ や $\mathrm{NiFe}$ でも同様に $\mathrm{Fe}$ が 含まれるため, ダイヤモンド界面で反応が起きている可能 性があるが, $\mathrm{Fe}$ の比率が小さい為影響が少ないと考えられ る.この問題を回避する方法の一つとしては, 磁性材料の 製膜を電子ビーム蒸着法などで行うことが考えられる.

半導体への効率的なスピン注入を行うには, 半導体/強磁 性体接合において低い $\Phi_{\mathrm{B}}$ が必要であると考えられている 16). 理論計算から半導体/強磁性体接合で磁気抵抗効果(MR) は $\Phi_{\mathrm{B}}$ が $0.6 \mathrm{eV}$ 以下で観測され， $\Phi_{\mathrm{B}}$ が減少するほど $\mathrm{MR}$ 值は増加する事が示されている ${ }^{17)}$. 一方, 水素終端ダイヤ モンド/強磁性体接合の場合は, Co や $\mathrm{NiFe}$ で仕事関数が大 きく, 小さな $\Phi_{\mathrm{B}}(<0.6 \mathrm{eV})$ が得られている.これらの結果 から, 我々は $\mathrm{Co}$ や $\mathrm{NiFe}$ のような仕事関数の大きな金属が ダイヤモンドへのスピン注入におけるスピン源として適し ていると考えており，これらの強磁性体を用いた接合によ りスピントランジスタに代表されるスピンデバイスの作製 が可能となると考えている。

\section{4. 結論}

本研究では, $\mathrm{Co1} \times \mathrm{F}$ ex や Ni1 $\mathrm{xFe}$ ( $(\mathrm{x}=0$ ～1)を強磁性体に用い水素 終端ダイヤモンド強磁性体接合を作製し, そのショットキ一特性 について調査した. $\mathrm{I}-\mathrm{V}$ 特性のフィッティングから得られた $\Phi_{\mathrm{B}}$ は明瞭な仕事関数依存性を示した. これらの結果は, 水素終端ダ イヤモンドでは適当な $\Phi_{\mathrm{M}}$ を持つ強磁生体を選択することにより $\Phi_{\mathrm{B}}$ の制御が可能であることを示している. また，仕事関数が大き な $\mathrm{Co}$ や $\mathrm{NiFe}(>5 \mathrm{eV})$ ほど低い $\Phi_{\mathrm{B}}(<0.6 \mathrm{eV})$ を示した. これら の結果から, 我々は水素終端ダイヤモンド半導体へのスピン注入 にはより大きい仕事関数を持つ強磁生体金属が適していると考え ている.

謝辞 本研究の一部は, 科学研究費補助金 $(20360005$, 22760250)及び(財)材料科学研究助成基金の支援を受けて 行われた。ここに感謝の意を表します. 


\section{References}

1) S. A. Wolf, D. D. Awschalom, R. A. Buhrman, J. M. Daughton, S. von Molnár, M. L. Roukes, A. Y. Chtchelkanova, and D. M. Treger, Science 294 (2001) 1489.

2) S. P. Dash, S. Sharma, R. S. Patel, M. P. Jong and R. Jansen, Nature 462 (2009) 491.

3) J. Isberg, J. Hammersberg, E. Johansson, T. Wikstrom, D. J. Twitchen, A. J. Whitehead, S. E. Coe, and A. Scarsbrook: Science 297 (2002) 1670.

4) K. Ueda, M. Kasu, Y. Yamauchi, T. Makimoto, M. Schwitters, D. J. Twitchen, G. A. Scarsbrook, and S. E. Coe: IEEE Electron Device Lett. 27 (2006) 570.

5) M. Kasu, K. Ueda, H. Ye, Y. Yamauchi, S. Sasaki, and T. Makimoto: Electron. Lett. 41 (2005) 1249.

6) T. H. Borst and O. Weis, Diamond Relat. Mater. 4 (1995) 948.

7) G. Schmidt, D. Ferrand, L. W. Molenkamp, A. T. Filip and B. J. van Wees, Phys. Rev. B 62 (2000) R4790.

8) J. Barjon, T. Tillocher, N. Habka, O. Brinza, J. Achard, R. Issaoui, F. Silva, C. Mer and P. Bergonzo, Phys. Rev. B, 83 (2011) 073201.

9) K. Hayashi, S. Yamanaka, H. Okushi, and K. Kajimura, Appl. Phys. Lett. 68 (1996) 376.

10) H. Umezawa, T. Saito, N. Tokuda, M. Ogura, S-G. Ri, H. Yoshikawa, and S. Shikata, Appl. Phys. Lett. 90 (2007) 073506.

11) H. B. Michaelson, J. Appl. Phys. 48 (1977) 4729.

12) J. B. Bauman and R. Nemanich, J. Appl. Phys. 83 (1998) 2072.

13) S. Yamanaka, D. Takeuchi, H. Watanabe, H. Okushi, and K. Kajimura, Diamond Relat. Mater. 9 (2000) 956.

14) M. Aoki and H. Kawarada, JJAP Vol.33,708 (1994)

15) P-C. Huang, W-C. Shin, H-C. Chen and I-N. Lin, J. Appl. Phys. 109 (2011) 084309.

16) J. D. Albrecht and D. L. Smith, Phys. Rev. B. 68 (2003) 035340 .

17) R. Jansen and B. C. Min, Phys. Rev. Lett. 99 (2007) 246604.

2011年11月7日受理，2012年1月18日再受理，2012年5月17日採録 